\title{
RITUAL PEMBUATAN MINYAK URUT KARO DI DESA JUMAPADANG KECAMATAN BARUSJAHE KABUPATEN KARO
}

\author{
Lisna Perodika Br Barus \\ Alumni Prodi. Pendidikan Antropologi Fakultas Ilmu Sosial Unimed \\ lisnaperodikabarus@gmail.com
}

\begin{abstract}
Abstrak
Artikel ini merupakan hasil penelitian yang menjelaskan tentang bahan-bahan untuk membuat minyak urut Karo, proses ritual pembuatan minyak urut Karo, tujuan ritual yang dilakukan dalam pembuatan minyak urut Karo, orang yang dapat melakukan ritual pembuatan minyak urut Karo yang terdapat di Desa Jumapadang, Kecamatan Barusjahe, Kabupaten Karo. Jenis penelitian ini adalah penelitian kualitatif yang bersifat deskriptif. Teknik pengumpulan data yang digunakan adalah observasi, wawancara mendalam dan dokumentasi. Berdasarkan hasil penelitian diketahui bahwa bahan-bahan untuk membuat minyak urut Karo adalah minyak goreng, minyak kelapa hijau, rempah ratus, jeruk purut/daun jeruk purut, panglai, kencur, bawang merah, bawang putih, lada, pala, sarang wallet, daun kapal-kapal, jambar api, tawan gegeh, tawar ipuh, bulung nilam, gagaten harimau, akar pinang, akar riman, akar bambu, alang-alang, akar pengkih, akar enau, kemangi, tawan gegeh, kunyit dan pinang. orang yang mengambil bahan-bahan ke dalam hutan adalah Bulang Tarigan dan jika Bulang Tarigan tidak mampu mengambilnya ke dalam hutan maka keluarga Nini Karo akan menyuruh orang upahan dan orang upahan tersebut bukan orang sembarangan karena hanya orang-orang tertentu yang mengenal dan mengetahui tempat untuk mengambil bahan-bahan yang dibutuhkan. Orang yang biasa disuruh oleh keluarga Nini Karo adalah Bulang Barus. Tujuan dari ritual pembuatan minyak urut karo di desa Jumapadang adalah agar minyak urut Karo tersebut mampu menyembuhkan penyakit-penyakit yang diyakini berasal dari roh-roh gaib atau penyakit yang dikirim oleh orang melalui cara-cara gaib dan meminta perlindungan kepada arwah para leluhur. Orang-orang yang dapat melalukan ritual pembuatan minyak urut Karo adalah salah satu keturunan yang dipilih oleh nenek moyang mereka dan diberi petunjuk melalui mimpi. Orang yang dipilih tidak boleh menolak karena jika menolak keluarganya akan mendapat musibah dan tidak akan dilindungi lagi oleh roh-roh nenek moyang.
\end{abstract}

Kata Kunci: Ritual, Minyak Urut Karo, Roh Gaib, Arwah Leluhur

\section{PENDAHULUAN}

Setiap etnis memiliki kebudayaan yang berbedabeda, bagitu juga dengan pemanfaatan pengobatan tradisional.Kesehatan merupakan suatu kebutuhan yang mendasar bagi kehidupan manusia. Apabila kesehatan terganggu maka aktivitas sehari-hari akan terganggu. Proses penyembuhan dan perawatan kesehatan, banyak ditemukan obat-obatan kesehatan yang bersifat alami selain pengobatan modern. Etnis Karo memiliki keyakinan bahwa obat tradisional Karo sangat bermanfaat untuk menjaga daya tahan tubuh atau meningkatkan kesehatan.Meskipun kemajuan teknologi kedokteran dan pengobatan modern pada saat ini sangat pesat, etnis Karo tetap menggunakan pengobatan tradisional.Pengobatan alternatif yang sering digunakan dan dipercayai untuk menyembuhkan penyakit dalam kebudayaan etnis Karo, salah satunya adalah Minyak Urut Karo atau sering disebut minak pengalun. Minyak Urut Karo atau Minak pengalun merupakan warisan yang telah digunakan turun-temurun sejak dahulu.

Etnis Karo masih menyakini bahwa hidup mereka di pengaruhi oleh roh-roh gaib dan untuk itu mereka masih sering melakukan upacara ritual. Etnis Karo juga memiliki ritual tersendiri untuk membuat Minak Pengalun atau Minyak Urut Karo khusunya Minyak Urut Karo Yang Ada di Desa Jumapadang Kecamatan Barusjahe Kabupaten Karo. Minyak Urut Karo ini memiliki keistimewaan dan keunikan yang pada umumnya tidak dimiliki minyak urut lainnya. Beberapa bahan yang dibutuhkan untuk membuat minyak urut ini sulit ditemukan, karena harus diambil ke hutan-hutan dan hanya orang-orang tertentu yang mengenalinya. Ritual dalam pembuatan minyak urut ini dilakukan dengan tujuan agar minyak urut ini mampu mengobati penyakit yang berasal dari roh-roh gaib, berbeda dengan minyak urut biasa. Ritual pembuatan minyak urut Karo ini hanya dapat dilakukan oleh orang-orang tertentu karena memiliki persyaratan tertentu yang harus dipenuhi. Penggunaan minyak urut memiliki pantangan-pantangan tertentu, jika pantangannya dilarang, fungsi minyak urut tersebut akan hilang.

Adapun yang menjadi tujuan penulisan artikel ini adalah untuk mengetahui bahan-bahan dalam pembuatanminyak urut Karo yang terdapat di Desa Juma Padang, Kecamatan Barusjahe Kabupaten Karo, 
mengetahui proses ritual dalam pembuatan minyak urut Karo yang terdapat di Desa Juma Padang, Kecamatan Barusjahe Kabupaten Karo, untuk mengetahui tujuan ritual yang dilakukan dalam pembuatan minyak urut Karo yang terdapat di Desa Juma Padang, Kecamatan Barusjahe Kabupaten Karo, dan untuk mengetahui orang yang dapat melakukan ritual dalam pembuatan Minyak Urut Karo yang terdapat di Desa Juma Padang, Kecamatan Barus Jahe Kabupaten Karo.

\section{METODE PENELITIAN}

Untuk menjawab permasalahan penelitian, peneliti menggunakan metode penelitian kualitatif dengan pendekatan deskriptif kualitatif.

Maryaeni (2005:58) menyatakan bahwa: "Metode merupakan cara yang di tempuh peneliti dalam menemukan pemahaman sejalan dengan fokus dan tujuan yang di tetapkan".

Selanjutnya Moleong (2012:6) menyatakan bahwa : "Penelitian kualitatif adalah penelitian yang bermaksud untuk memahami fenomena tentang apa yang dialami oleh subjek penelitian misalnya perilaku, persepsi, motivasi, tindakan, dll., secara holistik, dan dengan cara deskripsi dalam bentuk kata-kata dan bahasa, pada suatu konteks khusus yang alamiah dan dengan memanfaatkan berbagai metode alamiah."

Menurut Bogdan dan Taylor (1975) dalam Moleong (2007:4) mengemukakan bahwa metodologi kualitatif sebagai prosedur penelitian yang menghasilkan data deskriptif berupa kata-kata tertulis atau lisan dari orang-orang dan perilaku yang dapat diamati.

Sesuai dengan yang dikemukakan oleh Moleong, maka penelitian ini telah mendeskripsikan setiap fenomena tentang ritual pembuatan minyak urut Karo di Desa Jumapadang. Oleh karena sifat penelitian yang deskriptif, maka data-data yang telah dikumpulkan adalah data kualitatif. Data kualitatif yang dimaksudkan dalam hal ini adalah segala informasi baik itu tentang kata-kata maupun tindakan dari subjek dan objek penelitian yang berkaitan dengan rumusan masalah.

Selanjutnya untuk menyempurnakan hasil penelitian tersebut, maka peneliti menambah beberapa literatur yang berhubungan dengan judul peneliti, yaitu berupa artikel, karya ilmiah, internet, buku-buku, jurnajurnal mengenai ritual, upacara adat dan literatur lainnya yang berhubungan dengan hal yang di teliti.

\section{HASIL DAN PEMBAHASAN}

Bahan-Bahan Yang Digunakan Dalam Pembuatan Minyak Urut Karo Yang Terdapat Di Desa Jumapadang Kecamatan Barusjahe Kabupaten Karo.

Etnis Karo merupakan etnis tradisional sehingga dalam pengobatan untuk mengatasi suatu penyakit, etnis Karo masih lebih memilih menggunakan pengobatan tradisional. Karena etnis Karo menyakini pengobatan tradisional jauh lebih baik dibandingkan dengan pengobatan modern. Pengobatan tradisional diyakini tidak memiliki efek samping sedangkan pengobatan modern memiliki efek samping tertentu.
Bahan-bahan dalam pembuatan minyak urut Karo di desa Jumapadang adalah minyak goreng, minyak kelapa hijau, rempah ratus, jeruk purut/daun jeruk purut, panglai, kencur, bawang merah, bawang putih, lada, pala, sarang wallet, daun kapal-kapal, jambar api, tawan gegeh, tawar ipuh, bulung nilam, gagaten harimau, akar pinang, akar riman, akar bambu, alang-alang, akar pengkih, akar enau, kemangi, tawan gegeh, kunyit dan pinang.

Orang yang mengambil bahan-bahan ke dalam hutan adalah Bulang Tarigan ( Suami Nini Karo ) dan jika Bulang Tarigan tidak mampu mengambilnya ke dalam hutan maka keluarga Nini Karo akan menyuruh orang upahan dan orang upahan tersebut bukan orang sembarangan karena hanya orang-orang tertentu yang mengenal dan mengetahui tempat untuk mengambil bahan-bahan yang dibutuhkan. Orang yang biasa disuruh oleh keluarga Nini Karo adalah Bulang Barus.

\section{Proses Pelaksanaan Ritual Pembuatan Minyak Urut Karo Yang Terdapat Di Desa Jumapadang Kecamatan Barusjahe Kabupaten Karo.}

Etnis Karo adalah salah satu etnis yang memiliki beragam kebudayaan, Etnis Karo merupakan salah satu etnis yang masih menganut kepercayaan tradisional Karo (Pemena) sebelum masuknya agama ke tanah Karo. Wujud dari kepercayaan tersebut adalah etnis Karo masih melakukan ritual-ritual yang dilakukan dengan berbagai tujuan yang ingin dicapai salah satu diantaranya adalah ritual pembuatan minyak urut Karo. Ritual pembuatan minyak urut Karo sama seperti halnya dengan ritual lainnya yang juga memiliki prosesi dan pelaksanaannya dan benda-benda pendukung ritual.

Proses ritual pembuatan minyak urut Karo di desa Jumapadang adalah setelah semua peralatan dan bahanbahan disiapkan, masing-masing anggota keluarga mengambil bagian masing-masing. Bahan-bahan seperti jeruk purut/daun jeruk purut, daun kapal-kapal, jambar api, bulung nilam, gagaten harimau dan kemangi di irisiris dengan menggunakan pisau tumpu lada. Bahan-bahan seperti rempah ratus, panglai, bawang merah, bawang putih, lada, pala, kunyit dan pinang ditumbuk hingga halus. Bahan-bahan seperti tawan gegeh, akar pinang, akar bambu, akar riman, akar pengkih dan alang-alang ditumbuk hingga pecah. Setelah semua bahan-bahan disatukan dalam satu wadah minyak urut Karo tersebut siap untuk dimasak. Belau cawir dan Perak disiapkan dan pada saat minyak urut Karo mulai dimasak mantramantra akan diucapkan untuk mengundang roh nenek moyang.

Mantera yang dibacakan berbunyi:

"okam nini sierkuasa

Berekenndulah gegeh ras kesehaten

Ibas kami makeken minak enda

Ras pedauh kam kerina

Kuasa-kuasa jahat ras kerina pinakit

Silit ibas daging kula kami

Endam pemindon kami nini

Gelah sura-sura kami tersehi.

Bujur..."

Artinya: 
Oh Nini yang berkuasa

Berikanlah kepada kami kekuatan dan kesehatan

Dalam memakai minyak urut ini

Dan jauhkanlah kami semua

Dari roh-roh jahat dan segala penyakit

Yang ada didalam tubuh kami

Inilah permohonan kami

Semoga niat kami tercapai

Amin ...

\section{Fungsi Melakukan Ritual Pembuatan Minyak Urut Karo di Desa Jumapadang Kecamatan Barusjahe Kabupaten Karo}

Ritual adalah suatu kegiatan yang dilakukan manusia yang bertujuan untuk berhubungan dengan dunia gaib dan roh-roh gaib dan dilakukan dengan cara dan maksud yang berbeda-beda tergantung apa yang diinginkan manusia dalam melakukan ritual tersebut.

Fungsi utama minyak urut ini adalah mengobati penyakit yang dianggap berasal dari roh-roh gaib atau penyakit yang dikirim orang lain melalui cara-cara gaib dan cara pengunaannya adalah dioleskan atau diurut. Minyak urut Karo ini juga mampu mengobati batuk dan cara penggunaanya adalah diminum sebanyak 1 sendok makan sebelum tidur. Minyak urut Karo ini juga berkhasiat untuk mengobati pegal-pegal karena terbuat dari rempah-rempah asli.

Masyarakat Karo meyakini bahwa suatu penyakit tidak hanya bisa disebabkan oleh factor-faktor yang dapat diterima akal manusia, seperti penyakit-penyakit pada umumnya, disamping penyakit yang dapat kita ketahui penyebabnya, ternyata ada juga penyakit yang tidak tahu asal-usulnya dan apa penyebabnya, penyakit tersebut adalah penyakit yang disebabkan oleh mahluk gaib atau disebabkan oleh orang yang sengaja mengirim penyakit melalui cara-cara gaib.

Etnis Karo merupakan salah satu etnis yang masih meyakini akan adanya kekuatan-kekuatan gaib yang mempengaruhi kehidupan mereka. Etnis Karo masih sering melakukan ritual-ritual yang bertujuan untuk berkomunikasi dengan roh-roh gaib dan dalam melaksanakan ritual tersebut ada syarat-syarat yang harus dipenuhi contohnya dalam ritual pembuatan minyak urut Karo.

Ritual pembuatan minyak urut Karo ini hanya dapat dilakukan oleh orang-orang yang telah dipilih memiliki alat-alat yang dibutuhkan saat melakukan ritual seperti perak dan pisau tumpu lada. Keluarga Nini Karo, Nini Biring dan Nini Ginting merupakan keluarga yang sampai saat ini masih melakukan ritual dalam pembuatan minyak urut tersebut karena mereka memiliki Perak dan Pisau Tumpu Lada warisan dari nenek moyang mereka. Mereka dibantu oleh anggota keluarga masing-masing dalam menyiapkan bahan yang dibutuhkan saat membuat minyak urut Karo tersebut.

Tujuan dari ritual pembuatan minyak urut Karo di desa Jumapadang adalah agar minyak urut Karo tersebut mampu menyembuhkan penyakit-penyakit yang diyakini berasal dari roh-roh gaib atau penyakit yang dikirim oleh orang melalui cara-cara gaib dan meminta perlindungan kepada arwah para leluhur.

\section{PENUTUP}

Berdasarkan hasil dari penelitian yang sudah dilakukan, maka peneliti dapat membuat kesimpulan.

1. Berdasarkan penelitian mengenai ritual pembuatan minyak urut Karo, maka yang menjadi bahan-bahan dalam pembuatan minyak urut Karo di desa Jumapadang adalah minyak goreng, minyak kelapa hijau, rempah ratus, jeruk purut/daun jeruk purut, panglai, kencur, bawang merah, bawang putih, lada, pala, sarang wallet, daun kapal-kapal, jambar api, tawan gegeh, tawar ipuh, bulung nilam, gagaten harimau, akar pinang, akar riman, akar bambu, alangalang, akar pengkih, akar enau, kemangi, tawan gegeh, kunyit dan pinang.

2. Berdasarkan penelitian mengenai ritual pembuatan minyak urut Karo, maka orang yang mengambil bahan-bahan ke dalam hutan adalah Bulang Tarigan ( Suami Nini Karo ) dan jika Bulang Tarigan tidak mampu mengambilnya ke dalam hutan maka keluarga Nini Karo akan menyuruh orang upahan dan orang upahan tersebut bukan orang sembarangan karena hanya orang-orang tertentu yang mengenal dan mengetahui tempat untuk mengambil bahan-bahan yang dibutuhkan. Orang yang biasa disuruh oleh keluarga Nini Karo adalah Bulang Barus.

3. Berdasarkan penelitian mengenai ritual pembuatan minyak urut Karo, maka tujuan dari ritual pembuatan minyak urut Karo di desa Jumapadang adalah agar minyak urut Karo tersebut mampu menyembuhkan penyakit-penyakit yang diyakini berasal dari roh-roh gaib atau penyakit yang dikirim oleh orang melalui cara-cara gaib dan meminta perlindungan kepada arwah para leluhur.

4. Berdasarkan penelitian mengenai ritual pembuatan minyak urut Karo, maka orang-orang yang dapat melalukan ritual pembuatan minyak urut Karo adalah salah satu keturunan yang dipilih oleh nenek moyang mereka dan diberi petunjuk melalui mimpi. Orang yang dipilih tidak boleh menolak karena jika mereka menolak keluarga mereka akan mendapat musibah dan tidak akan dilindungi lagi oleh roh-roh nenek moyang mereka.

\section{DAFTAR PUSTAKA}

Agus, Bustanuddin. 2007. Agama Dalam Kehidupan Manusia Pengantar Antropologi Agama. Jakarta : Raja Grafindo Persada.

Dhavamony, 2002. Fenomologi Agama. Yogyakarta : Kanisius.

Elvayeni, 2012. Studi Etnobotani Penggunaan Tanaman Obat Tradisional Etnis Karo Di Desa Jarang Uda Kecamatan Merdeka Kabupaten Karo. Skripsi.UNIMED.

Foster Anderson, 2009. Antropologi Kesehatan. Jakarta : UI Press. 
Husaini, Usman.2009. Metodologi Penelitiam Sosial.Jakarta : Bumi Aksara.

Koentjaraningrat, 1972. Beberapa Pokok Antropologi Sosial. Yogyakarta. Universitas Gajah Mada.

Koentjaraningrat, 1987. Sejarah Antropologi 1. Jakarta : Universitas Indonesia

Koentjaraningrat. 1992. Beberapa Pokok Antropologi Sosial. Jakarta : Dian Rakyat.

Koentjaraningrat. 1997. Pengantar Antropologi pokokpokok etnografi II. Jakarta : Rineka Cipta.

Koentjaraningrat. 2009. Pengantar Ilmu Antropologi. Jakarta : Rineka Cipta.

Kuntjara, Ester. 2006. Penelitian Kebudayaan Sebuah Panduan Praktis. Jakarta : Graha Ilmu.

Maryaeni, 2005. Metode Penelitian Kebudayaan. Jakarta : Bumi Aksara.

Moleong Lexy, J. 2012. Metode Penelitian Kualitatif. Bandung : Remaja Rosdakarya Offset.

Muzaham, Fauzi. 1995. Memperkenalkan Sosiologi Kesehatan. Jakarta : UI Press.

Roiman, 2014. Analisis Kandungan Logam Cu, Fe, dan Fb Dalam Obat Tradisional Minyak Karo. Skripsi.USU.

Priati, Yayat. 2010. Pengenalan Dini Obat Alami. Tangerang : Panca Anugrah Sakti.

Sarjani, 2010. Dinamika Peradatan Orang Karo. Medan :Si BNB Press.

Sarjani, 2012. Mutiara Hijau Budaya Karo. Medan : Si BNB Press.

Soekanto, Soerjono. 2007. Sosiologi Suatu Pengantar. Jakarta : Raja Grafindo Persada.

Zuhelmi, 2012. Kearifan Lokal Masyarakat Etnis Gayo Terhadap Pemanfaatan Tumbuhan Obat Di Desa Wihnongkal Kecamatan Kute Pinang Kabupaten Aceh Tengah. Skripsi.UNIMED.

Sumber lain :

www.obat-tradisional.com diakses pada 19 Januari 2015, 13:10:38 Wib

m.kompasiana.com/post/read/63681/minak-pengalunramuan-minyak-tradisional-dari-tanah-Karo.html di akses pada 20/01/2015 12.05 Wib. 